\title{
Acute pro-B-Cell lymphoblastic leukemia transformed from myelodysplastic syndrome with an ASXL1 missense mutation: A case report with literature review
}

\author{
ZHI-PING GUO, YAN-HONG TAN, JIAN-LAN LI, ZHI-FANG XU, XIU-HUA CHEN and LIAN-RONG XU \\ Department of Hematology, The Second Hospital of Shanxi Medical University, Taiyuan, Shanxi 030001, P.R. China
}

Received October 30, 2017; Accepted April 13, 2018

DOI: $10.3892 / 01.2018 .8546$

\begin{abstract}
The development of acute lymphoblastic leukemia (ALL) from myelodysplastic syndrome (MDS) is a very rare event. The current report presents a rare case of a 33-year-old man who was diagnosed with MDS with multiple-lineage dysplasia (MDS-MLD) that transformed into pro-B-ALL. A missense mutation (S1231F) of the additional sex combs like 1, transcriptional regulator gene was identified, which may have a substantial role in the progression, however does not act as an unfavorable prognostic marker. The patient died during induction chemotherapy. The present study further conducted an analysis on 30 patients to determine progression to ALL. Patients were predominantly male $(76.7 \%, 23 / 30)$ with a median age of 56 years (3-90 years). The median time to transformation was 5.5 months (2-50 months). The most common type of MDS with ALL transformation comprised of MDS-excess blasts (MDS-EB; 40\%, 12/30), MDS with single-lineage dysplasia (MDS-SLD; 30\%, 9/30) and MDS with ring sideroblasts (MDS-RS; 16.7\%, 5/30). The majority of the patients transformed to B-cell $(66.7 \%, 16 / 24)$ followed by T-cell $(33.3 \%, 8 / 24)$ ALL. From the 25 cases where data was available, the complete remission rate was $75 \%(15 / 20)$ with ALL-directed chemotherapy and the median remission duration was 15 months (range 4.5 to 51 months). However, the results indicated that ALL following MDS is characterized by a high rate of early death $(20 \%, 5 / 25)$.
\end{abstract}

\section{Introduction}

Myelodysplastic syndromes (MDSs) are a heterogeneous clonal disease originating in hematopoietic stem cells and characterized by myeloid dysplasia, impaired differentiation, and peripheral cytopenia (1), with estimated incidence rate

Correspondence to: Dr Lian-Rong Xu, Department of Hematology, The Second Hospital of Shanxi Medical University, 382 WuYi Road, Taiyuan, Shanxi 030001, P.R. China

E-mail: 13593131660@163.com

Key words: myelodysplastic syndrome, acute lymphoblastic leukemia, ASXL1 mutation of 4.3 per 100,000 (2). MDS is recognized as a preleukaemic event in which neoplastic clones are established. It frequently evolves to acute leukemia in 20-40\% of MDS patients (3). MDS originates from multipotent hematopoietic stem cells, which can give rise to both lymphoid and myeloid leukemic cells (4). However, progression of MDS to acute lymphocytic leukemia (ALL) is extremely rare, occurring in less than $1 \%$ of cases $(3,5,6)$. To date, there are only 29 reported cases of MDS progressing to ALL. The pathogenesis and prognosis of ALL transformed from MDS is still unclear.

With the advancement of next-generation sequencing, it is possible to identify new somatic mutations that have a potential impact on MDS patients. Mutations in additional sex combs like-1 (ASXL1), an unfavorable prognostic marker, occurs with a frequency of $10-20 \%$ in MDS, with $70 \%$ being frameshift mutations and $30 \%$ being heterozygous point mutations (7-9). Frameshift or nonsense mutations correlated with shorter survival rates and a higher risk of leukemic transformation $(8,10,11)$. However, the clinical significance of ASXL1 missense mutations is still questionable. Further research to the role of ASXL1 missense mutations in MDS is required.

In this report, we describe a Chinese male patient harboring an ASXL1 missense mutation. He was diagnosed with pro-B-ALL, transformed from MDS with multiple-lineage dysplasia (MDS-MLD). Furthermore, in order to gain full insight into the clinical features and treatment outcome of ALL transformed from MDS, we analyzed previously reported data from 30 patients for such progression.

\section{Case report}

A 33-year-old Chinese man was evaluated for thrombocytopenia in July 2013. On examination, he had splenomegaly. Initial blood counts revealed the following; hemoglobin, $123 \mathrm{~g} / 1$; leukocyte count, $7.23 \times 10^{9} / 1$; and platelet count, $23 \times 10^{9} / 1$. Bone marrow examination (Fig. 1) revealed augmented cellularity and trilineage dysplasia with no increase in myeloblasts dysplasia. Cytogenic testing revealed a normal karyotype 46, XY. Using specific and comprehensive fluorescent in situ hybridization (FISH) probe panels showed a lack of demonstrable cytogenetic abnormalities. The patient was diagnosed with MDS-MLD using the World Health Organization classification. Using the revised International Prognostic Scoring System (IPSS-R), he was classified into the low risk category. 


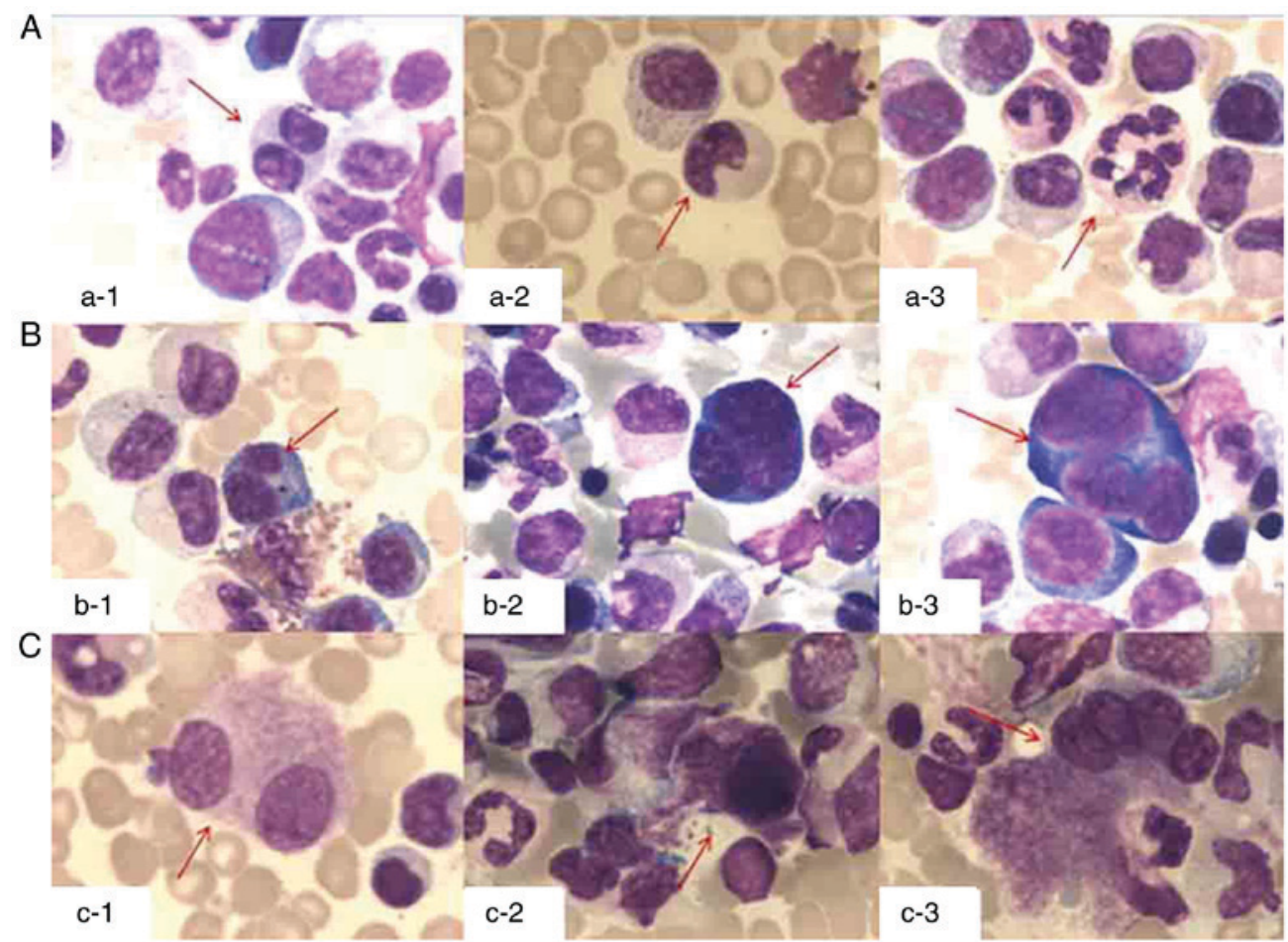

Figure 1. MDS-MLD at first admission. BM aspirate smears (Wright-Giemsa stain, $\mathrm{x} 1,000$ ) revealed hypercellular marrow with dysplastic changes in 3 hematopoietic cell lineages. (A) Granulocytic dysplastic changes, including pseudo Pelger anomaly of the nucleus (a-1), degranulation (a-2), and abnormalities of nuclear segmentation (a-3). (B) Erythroid dysplasia, including binucleation (b-1) and multinuclearity (b-2 and -3). (C) Megakaryocytes exhibited dysplastic changes like small binucleate megakaryocyte (c-1), micromegakaryocytes (c-2) and megakaryocyte with isolated multi-nuclei (c-3).

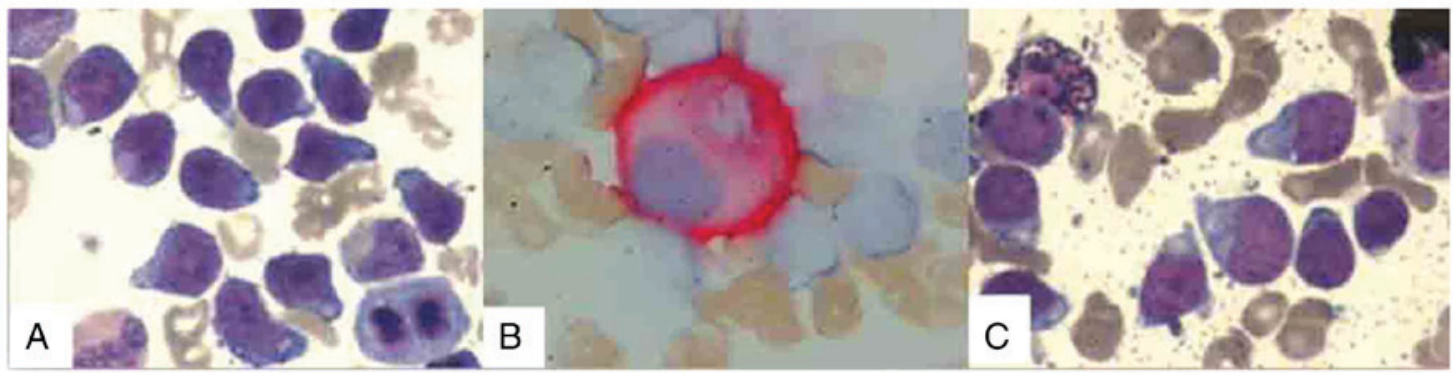

Figure 2. ALL at second admission. BM aspiration smear (Wright-Giemsa stain, $\mathrm{x} 1,000)$ exhibits a markedly increased number of lymphoblasts (A) and micromegakaryocytes by CD41 monoclonal antibody immune enzyme staining (B). The lymphoblasts were $5 \%$ positive for POX staining (C).

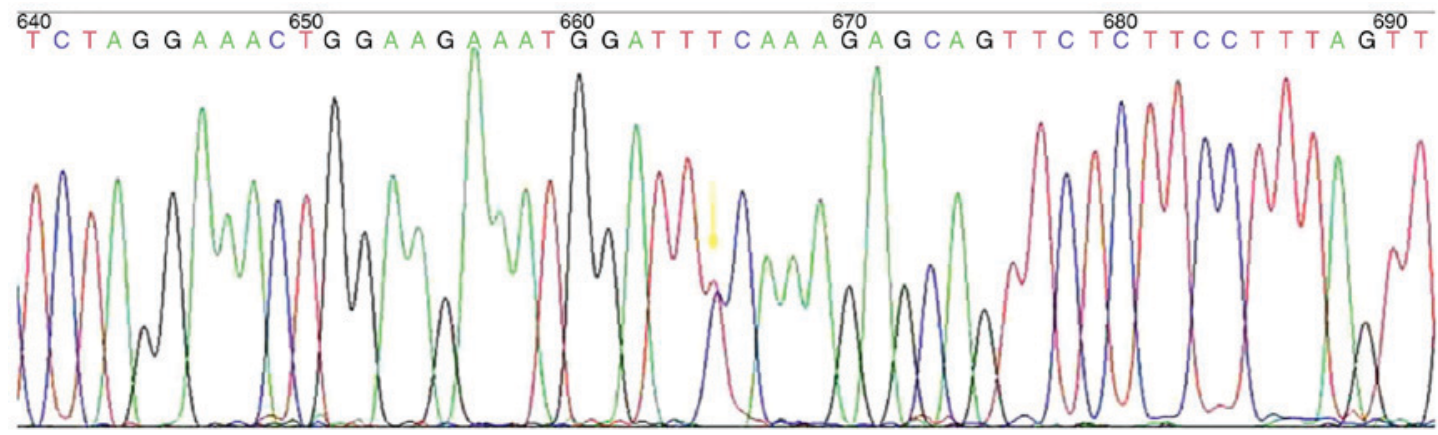

Figure 3. Point mutation TCC $>$ TTC in codon 1231 of ASXL1 gene.

The patient exhibited persistent thrombocytopenia with progressing anemia. He did not receive any treatment.

After a 47-month history of prolonged bleeding and fatigue, his condition worsened abruptly. Blood counts demonstrated hemoglobin levels at $49 \mathrm{~g} / 1$; platelets at $5 \times 10^{9} / 1$; and leukocyte counts at $6.56 \times 10^{9} / 1$. Examination of bone marrow was consistent with a diagnosis of ALL, revealing 63.5\% blasts (Fig. 2A) with numerous micromegakaryocytes by CD41 monoclonal 
antibody immune enzyme staining (Fig. 2B). Cytochemical staining demonstrated that the blasts were 95\% negative for peroxidase (Fig. 2C). Cell surface markers analyzed by flow cytometry were positive for CD34, CD19, cCD79a, CD123, and CD38. The blasts also expressed CD33, a myeloid marker. Myeloid cell markers for CD117 and CD13 and T cell markers for cyCD3, CD5, and CD7 were not expressed. The blasts were also negative for CD10, CD15, CD11b, CD64, CD14, CD20, cTDT, cIgM, CD56 and cyMPO. Based on these markers, the patient was diagnosed with Pro-B-ALL. Karyotype analysis of bone marrow leukemic cells revealed normal chromosomes (46, XY). Gene rearrangements were not detected using reverse transcription-PCR.

In addition, known gene mutations associated with MDS were screened using next-generation sequencing techniques. Driver mutant genes include those of RNA splicing ( $S F 3 B 1$, $S R S F 2$ and U2AF1), DNA methylation (TET2, DNMT3A, and $I D H 1 / 2)$, chromatin modification (ASXL1 and EZH2), transcription regulation $(R U N X 1)$, DNA repair (TP53), and signal transduction (NRAS and KRAS). The patient harbored the point mutation TCC>TTC in codon 1231 of ASXL1 gene (Fig. 3), leading to a serine to phenylalanine substitution $(\mathrm{S} 1231 \mathrm{~F})$. Other genetic aberrations were not detected in this patient. Subsequently, the patient received chemotherapy beginning the day after bone marrow examination. Treatment regimen included prednisone, vincristine, cyclophosphamide and idarubicin. Unfortunately, the patient passed away due to severe pulmonary infection during the course of chemotherapy. Written informed consent for publication of data was obtained from patient's family.

\section{Discussion}

We performed an analysis of 30 patients with MDS transforming to ALL (summary in Table I). Clinical characteristics were similar with previous reports in literature $(12,13)$. Patients were predominantly male $(76.7 \%, 23 / 30)$ with a median age of 56 years (3-90 years). The median time to transformation was 5.5 months (2-50 months). The common types of MDS with ALL transformation include MDS-excess blasts (MDS-EB) $(40 \%, 12 / 30)$, MDS with single-lineage dysplasia (MDS-SLD) $(30 \%, 9 / 30)$ and MDS with ring sideroblasts (MDS-RS) $(16.7 \%, 5 / 30)$. Majority of the patients transformed to B-cell $(66.7 \%, 16 / 24)$ followed by T-cell $(33.3 \%, 8 / 24)$ ALL. Using immunophenotyping analysis of our 33 year old male patient, we confirmed the diagnosis of pro-B-ALL due to the bright uniform expression of CD19 and the absence of CD10 surface antigen. The coexpression of CD34 and CD33 myeloid antigens was consistent with the immunophenotypic subtype of pro-B-ALL. Our patient had absence of MLL1/AF4 and $\mathrm{BCR} / \mathrm{ABL}$ fusion genes, which correlates with a significantly better clinical outcome (14). Because of this, our patient was expected to have a good prognosis. However, after a period of prolonged fatigue and bleeding, his condition rapidly deteriorated and he eventually died of severe pulmonary infection due to excess myelosuppression during ALL-directed chemotherapy. His death may be attributed to the nature of MDS transformation.

Although AML evolved from MDS has a poor prognosis, ALL following MDS has not been associated with a poor prognosis as reported in the literature (15). However, due to the limited number of cases ( 9 cases), it is difficult to make any conclusions regarding prognosis. From the 25 cases of MDS transforming to ALL reported in the literature (Table I), 15 patients achieved complete remission (CR) and 1 achieved partial remission (PR). Two cases were refractory and 2 patients failed to achieve a CR after induction treatment. Four patients died during induction therapy and 1 died before therapy. Our results confirm that the complete remission (CR) rate $(75 \%$, 15/20) with ALL-directed chemotherapy and the median remission duration of 15 months (range 4.5 to 51 months) are similar with previous reports (15). However, ALL following MDS is characterized by a higher rate of early mortality $(20 \%$, $5 / 25)$.

Genetic aberrations appear to play an important role in the pathogenesis of MDS. ASXL1 gene mutations are one of the characteristic mutations observed for MDS. It encodes a highly conserved protein that belongs to the enhancer of trithorax and polycomb (ETP) genes, a gene family with dual functions in both epigenetic activation and repression of gene transcription (16). It contains several nuclear receptor binding motifs and a carboxy-terminal plant homeodomain (PHD) that is predicted to be truncated by frameshift mutations or nonsense mutations $(10,11)$. However, the clinical significance of missense mutations in ASXL1 is unknown. An ASXL1 missense mutation was detected in our patient. This ASXL1 missense mutation did not correspond with other gene mutations identified as adverse prognostic factors. We hypothesize that it may play a substantial role in the progression of our case. The function of ASXL1 is expected to be impaired by this missense mutation.

These novel genetic aberrations in MDS need to be further evaluated regarding their prognostic impact. In our patient, the time to transformation after primary diagnosis was much longer than the median observed. It seems that this missense mutation, unlike frameshift mutations of ASXL1, was not an unfavorable prognostic marker for patients with MDS, which is consistent with previous reports (9). Additional studies needs to be conducted to elucidate the influence of ASXL1 missense mutations on the prognosis of patients with MDS.

In summary, we report an ASXL1 missense mutation potentially leading to MDS-MLD transforming to pro-B ALL. This mutation might provide insight into the pathogenesis and prognosis of MDS. ALL following MDS responds well to ALL-directed therapy, but higher rates of early mortality are observed. The prognosis of ALL following MDS needs to be further validated using more uniformly treated patients within a given protocol. Identification of specific gene mutations will hopefully provide for better treatment strategies for this group of patients.

\section{Acknowledgements}

The authors would like to thanks the faculty members who analyzed the cytogenetic data.

\section{Funding}

Nor applicable. 


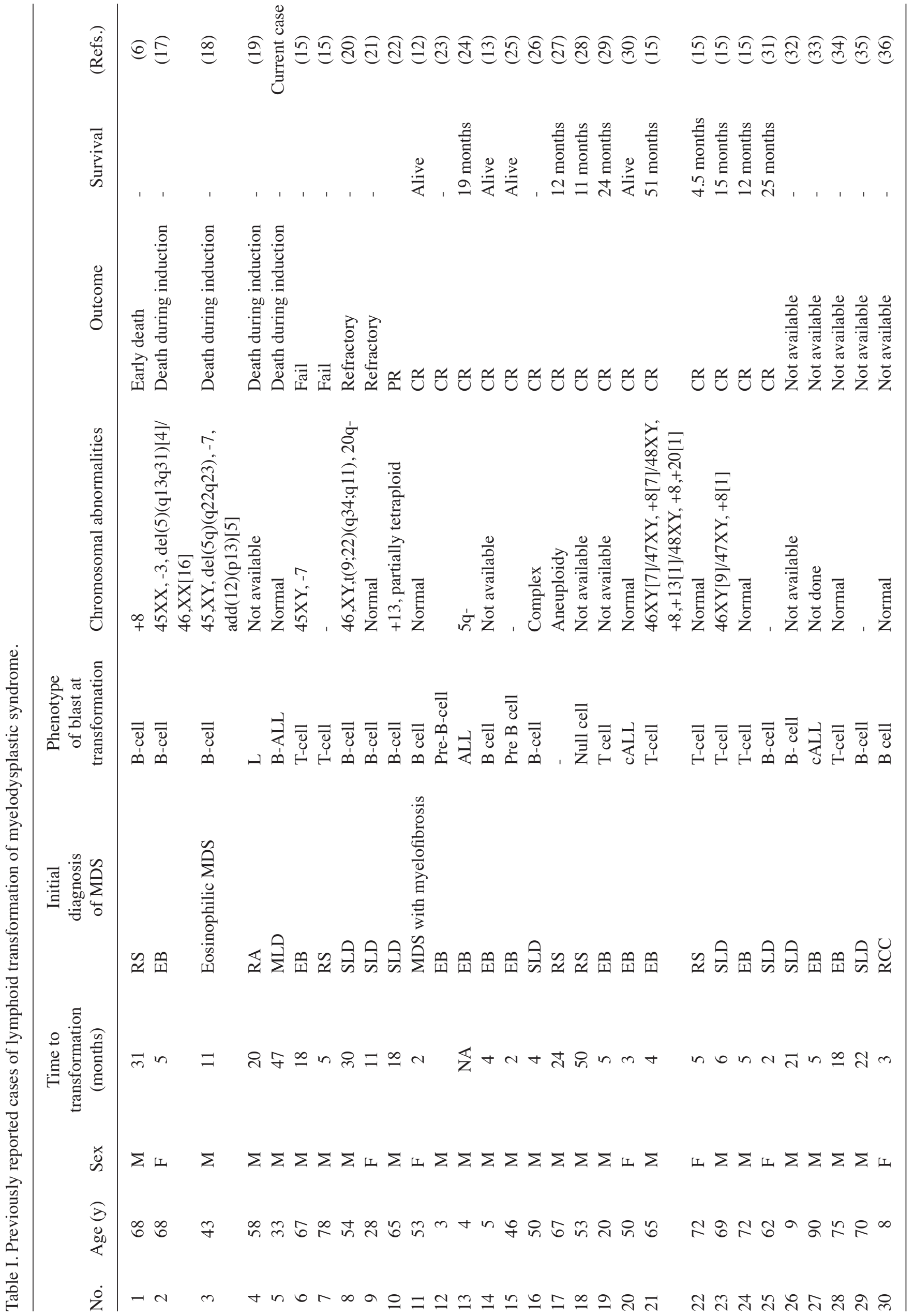




\section{Availability of data and materials}

All data generated or analyzed during this study are included in this published article.

\section{Authors' contributions}

LX and ZG analyzed and interpreted the patient data regarding the hematological disease. ZG was a major contributor in designing the work and writing the manuscript. YT and $\mathrm{XC}$ performed the PCR and next-generation sequencing. ZX analyzed the flow cytometric data. JL performed the bone marrow examination. All authors read and approved the final manuscript.

\section{Ethics approval and consent to participate}

The study was granted an exemption from requiring ethics approval from the ethics committee of the Second Hospital of Shanxi Medical University.

\section{Consent for publication}

Informed consent for publication was obtained from the family of the patient reported in current study.

\section{Competing interests}

The authors declare that they have no competing interests.

\section{References}

1. Nimer SD: Myelodysplastic syndromes. Blood 111: 4841-4851, 2008.

2. Visconte V, Selleri C, Maciejewski JP and Tiu RV: Molecular pathogenesis of myelodysplastic syndromes. Transl Med UniSa 8 19-30, 2014.

3. San Miguel JF, Hernández JM, González-Sarmiento R, González M, Sánchez I, Orfao A, Cañizo MC and López Borrasca A: Acute leukemia after a primary myelodysplastic syndrome: Immunophenotypic, genotypic, and clinical characteristics. Blood 78: 768-774, 1991.

4. Janssen JW, Buschle M, Layton M, Drexler HG, Lyons J, van den Berghe $\mathrm{H}$, Heimpel H, Kubanek B, Kleihauer E, Mufti GJ, et al: Clonal analysis of myelodysplastic syndromes: Evidence of multipotent stem cell origin. Blood 73: 248-254, 1989.

5. Orfao A, Ortuño F, de Santiago M, Lopez A and San Miguel J: Immunophenotyping of acute leukemias and myelodysplastic syndromes. Cytometry A 58: 62-71, 2004.

6. Disperati P, Ichim CV, Tkachuk D, Chun K, Schuh AC and Wells RA: Progression of myelodysplasia to acute lymphoblastic leukaemia: Implications for disease biology. Leuk Res 30: 233-239, 2006.

7. Gelsi-Boyer V, Trouplin V, Adélaïde J, Bonansea J, Cervera N, Carbuccia N, Lagarde A, Prebet T, Nezri M, Sainty D, et al: Mutations of polycomb-associated gene ASXL1 in myelodysplastic syndromes and chronic myelomonocytic leukaemia. Br J Haematol 145: 788-800, 2009.

8. Alvarez Argote $\mathrm{J}$ and Dasanu CA: ASXL1 mutations in myeloid neoplasms: Pathogenetic considerations, impact on clinical outcomes and survival. Curr Med Res Opin: 1-7, 2017 (Epub ahead of print).

9. Thol F, Friesen I, Damm F, Yun H, Weissinger EM, Krauter J, Wagner K, Chaturvedi A, Sharma A, Wichmann M, et al: Prognostic significance of $A S X L 1$ mutations in patients with myelodysplastic syndromes. J Clin Oncol 29: 2499-2506, 2011.
10. Fisher CL,Pineault N,Brookes C, Helgason CD, Ohta H,Bodner C, Hess JL, Humphries RK and Brock HW: Loss-of-function Additional sex combs like 1 mutations disrupt hematopoiesis but do not cause severe myelodysplasia or leukemia. Blood 115: 38-46, 2010.

11. Vainchenker W, Delhommeau F, Constantinescu SN and Bernard OA: New mutations and pathogenesis of myeloproliferative neoplasms. Blood 118: 1723-1735, 2011.

12. Algarni AA, Akhtari M and Fu K: Myelodysplastic syndrome with myelofibrosis transformed to a precursor B-cell acute lymphoblastic leukemia: A case report with review of the literature. Case Rep Hematol 2012: 207537, 2012.

13. Gupta V and Bhatia B: Transformation of myelodysplastic syndrome to acute lymphoblastic leukemia in a child. Indian J Hematol Blood Transfus 26: 111-113, 2010.

14. Cimino G, Elia L, Mancini M, Annino L, Anaclerico B, Fazi P, Vitale A, Specchia G, Di Raimondo F, Recchia A, et al: Clinico-biologic features and treatment outcome of adult pro-B-ALL patients enrolled in the GIMEMA 0496 study: Absence of the ALL1/AF4 and of the BCR/ABL fusion genes correlates with a significantly better clinical outcome. Blood 102: 2014-2020, 2003.

15. Escudier SM, Albitar M, Robertson LE, Andreeff M, Pierce S and Kantarjian HM: Acute lymphoblastic leukemia following preleukemic syndromes in adults. Leukemia 10: 473-477, 1996.

16. Fisher CL, Randazzo F, Humphries RK and Brock HW: Characterization of Asxl1, a murine homolog of Additional sex combs, and analysis of the Asx-like gene family. Gene 369: 109-118, 2006.

17. Sato N, Nakazato T, Kizaki M, Ikeda $Y$ and Okamoto $S$ : Transformation of myelodysplastic syndrome to acute lymphoblastic leukemia: A case report and review of the literature. Int J Hematol 79: 147-151, 2004.

18. Follows GA, Owen RG, Ashcroft AJ and Parapia LA: Eosinophilic myelodysplasia transforming to acute lymphoblastic leukaemia. J Clin Pathol 52: 388-389, 1999.

19. Inoshita T: Acute lymphoblastic leukemia following myelodysplastic syndrome. Am J Clin Pathol 84: 233-237, 1985.

20. Kohno T, Amenomori T, Atogami S, Sasagawa I, Nakamura H, Kuriyama K and Tomonaga M: Progression from myelodysplastic syndrome to acute lymphoblastic leukaemia with Philadelphia chromosome and p190 BCR-ABL transcript. Br J Haematol 93: 389-391, 1996.

21. Bonati A, Delia D and Starcich R: Progression of a myelodysplastic syndrome to pre-B acute lymphoblastic leukaemia with unusual phenotype. Br J Haematol 64: 487-491, 1986.

22. Ascensao JL, Kay NE, Wright JJ, Arthur D, Finkel B, Rydell R and Kaplan ME: Lymphoblastic transformation of myelodysplastic syndrome. Am J Hematol 22: 431-434, 1986.

23. Rossbach HC, Sutcliffe MJ, Chamizo W, Haag MM, Grana NH, Washington KR and Barbosa JL: Pre-B acute lymphoblastic leukemia in a 3-year-old boy with pre-acute myelogenous leukemia myelodysplastic syndrome: Cytogenetic evidence of common early progenitor cell ontogeny. J Pediatr Hematol Oncol 20: 347-352, 1998.

24. Bader-Meunier B, Miélot F, Tchernia G, Buisine J, Delsol G, Duchayne E, Lemerle S, Leverger G, de Lumley L and Manel AM: Myelodysplastic syndromes in childhood: Report of 49 patients from a French multicentre study. French society of paediatric haematology and immunology. Br J Haematol 92: 344-350, 1996.

25. Abruzzese E, Buss D, Rainer R, Pettenati MJ and Rao PN: Progression of a myelodysplastic syndrome to pre-B acute lymphoblastic leukemia: A case report and cell lineage study. Ann Hematol 73: 35-38, 1996.

26. Ikeda T, Sato K, Yamashita T, Kanai Y, Kuwada N, Matsumura T, Nakamura Y, Kimura F and Motoyoshi K: Burkitt's acute lymphoblastic leukaemia transformation after myelodysplastic syndrome. Br J Haematol 115: 69-71, 2001.

27. Hussein KK, Salem Z, Bottomley SS and Livingston RB: Acute leukemia in idiopathic sideroblastic anemia: Response to combination chemotherapy. Blood 59: 652-656, 1982.

28. Barton JC, Conrad ME and Parmley RT: Acute lymphoblastic leukemia in idiopathic refractory sideroblastic anemia: Evidence for a common lymphoid and myeloid progenitor cell. Am J Hematol 9: 109-115, 1980.

29. Naithani R,KumarR, Saxena R and Mahapatra M: Transformation of myelodysplastic syndrome to T-cell acute lymphoblastic leukemia in a young adult. Pediatr Hematol Oncol 26: 100-102, 2009. 
30. Berneman ZN, Van Bockstaele D, De Meyer P, Van der Planken M, Vertessen F, De Bock R and Peetermans ME: A myelodysplastic syndrome preceding acute lymphoblastic leukaemia. Br J Haematol 60: 353-354, 1985.

31. Lima CS, de Souza CA, Cardinalli IA and Lorand-Metze I: Lymphoblastic transformation of myelodysplastic syndrome. Sao Paulo Med J 115: 1508-1512, 1997.

32. Goel R, Kumar R and Bakhshi S: Transformation of childhood MDS-refractory anemia to acute lymphoblastic leukemia. J Pediatr Hematol Oncol 29: 725-727, 2007.

33. Nagler A, Brenner B and Tatarsky I: Secondary refractory anemia with excess of blasts in transformation terminating as acute lymphoblastic leukemia. Acta Haematol 76: 164-165, 1986.

34. Pereira AM, Tavares de Castro J, Santos EG, Perloiro MC and Catovsky D: T lymphoblastic transformation of refractory anaemia with excess of blasts. Clin Lab Haematol 7: 89-95, 1985.
35. Pajor L, Matolcsy A, Vass JA, Méhes G, Marton E, Szabó F and Iványi JL: Phenotypic and genotypic analyses of blastic cell population suggest that pure B-lymphoblastic leukemia may arise from myelodysplastic syndrome. Leuk Res 22: 13-17, 1998.

36. Koh YR, Cho EH, Park SS, Park MY, Lee SM, Kim IS and Lee EY: A rare case of transformation of childhood myelodysplastic syndrome to acute lymphoblastic leukemia. Ann Lab Med 33: 130-135, 2013.

This work is licensed under a Creative Commons Attribution-NonCommercial-NoDerivatives 4.0 International (CC BY-NC-ND 4.0) License. 